BACCI, L.; PICANÇO, M.C.; GUSMÃO, M.R.; BARRETO, R.W.; GALVAN, T.L. Inseticidas seletivos à tesourinha Doru luteipes (Scudder) utilizados no controle do pulgão verde em brássicas. Horticultura Brasileira, Brasília, v. 20, n. 2, p. 174 -179, junho 2.002.

\title{
Inseticidas seletivos à tesourinha Doru luteipes (Scudder) utilizados no controle do pulgão verde em brássicas
}

\author{
Leandro Bacci, Marcelo C. Picanço; Marcos Rafael Gusmão; Robert W. Barreto; Tederson Luiz Galvan \\ UFV, 36.571-000 Viçosa - MG. E-mail: picanco@mail.ufv.br; rbarreto@mail.ufv.br
}

\section{RESUMO}

Estudou-se a seletividade dos inseticidas acefato, deltametrina, dimetoato, metamidofós, paratiom metílico e pirimicarbe a ninfas de último estádio de Myzus persicae (Sulzer) (Homoptera: Aphididae), em relação a adultos, ninfas de primeiro, segundo e terceiro estádios de Doru luteipes (Scudder) (Dermaptera: Forficulidae). Pirimicarbe foi altamente seletivo em favor de todos os estádios do predador, sendo que os demais inseticidas foram medianamente seletivos em favor de adultos do predador. Deltametrina, paratiom metílico e dimetoato foram medianamente seletivos em favor de ninfas de terceiro estádio de D. luteipes, sendo que o mesmo ocorreu com os dois primeiros destes em relação a ninfas de primeiro e segundo estádios, respectivamente. Acefato foi pouco seletivo em favor de ninfas de segundo e terceiro estádios, sendo que o mesmo ocorreu com paratiom metílico, deltametrina e metamidofós em relação a ninfas de primeiro, segundo e terceiro estádios, respectivamente. Dimetoato e metamidofós foram mais tóxicos a ninfas de primeiro e segundo estádios do predador do que ao pulgão, sendo que o mesmo ocorreu com o acefato para ninfas de primeiro estádio. Adultos e ninfas de segundo e terceiro estádios de $D$. luteipes foram mais tolerantes ao acefato, paratiom metílico e pirimicarbe do que ninfas de primeiro estádio do predador. Ninfas de primeiro e segundo estádios apresentaram tolerância semelhante a deltametrina, dimetoato e metamidofós. As curvas de concentração-mortalidade de deltametrina, metamidofós e pirimicarbe (para todos os estádios de desenvolvimento de $D$. luteipes), dimetoato (para adultos e ninfas de primeiro e segundo estádios), paratiom metílico (para ninfas de primeiro e terceiro estádio) e acefato (para adultos), apresentaram maiores inclinações do que as curvas destes inseticidas para $M$. persicae.

Palavras-chave: Brassica oleracea, seletividade, controle biológico.

\begin{abstract}
Selective insecticides to the earwing Doru luteipes (Scudder) used for controlling the green peach aphid in Brassicae

The selectivity of the insecticides acephate, deltamethrin, dimethoate, methamidophos, methyl parathion, and pirimicarb were studied on the last nymphal phase of the green peach aphid Myzus persicae (Sulzer) (Homoptera: Aphididae) and on first, second, and third instar nymphs and adults of the Doru luteipes (Scudder) (Dermaptera: Forficulidae). Pirimicarb was highly selective in favor of all developmental stages of $D$. luteipes. Deltamethrin, methyl parathion and dimethoate were of median selectivity in favor of third instar nymphs of $D$. luteipes, as was also observed for the first two of these insecticides regarding to nymphs of first and second instars, respectively. Acephate was little selective in favor of second and third instars nymphs, and the same was observed for methyl parathion, deltamethrin and methamidophos to first, second and third instar nymphs, respectively. Dimethoate and methamidophos were more toxic to nymphs of first and second instars of the predator than to the last instar nymphs of the green peach aphid. D. luteipes adults and second and third instar nymphs were more tolerant to acephate, methyl parathion, and pirimicarb than first instar nymphs. D. luteipes first and second instar nymphs showed similar tolerance to deltamethrin, dimethoate, and methamidophos. Concentrationresponse curves for deltamethrin, methamidophos, and pirimicarb (to all development stages of $D$. luteipes), for dimethoate (to adults and first and second instar nymphs of the predator), for methyl parathion (to first and third instar nymphs of the predator), and for acephate (to adults of the predator) showed steeper slopes than the concentration-response curves of these insecticides established to M. persicae.
\end{abstract}

Keywords: Brassica oleracea, selectivity, biological control.

(Aceito para publicação em 26 de novembro de 2.001)

$\mathrm{O}$ pulgão Myzus persicae (Sulzer) (Homoptera: Aphididae) é um dos fatores chave de redução da produção das brássicas. Esse inseto causa grandes prejuízos pela sucção contínua de seiva, inoculação de toxinas no sistema vascular das plantas além da possibilidade de transmissão de viroses (CATIE, 1990). O seu controle é realizado principalmente por aplicações de inseticidas, sendo que o acefato, deltametrina, dimetoato, metamidofós, paratiom metílico e pirimicarbe, estão entre os principais produtos empregados pelos agricultores (Andrei, 1999).
Dentre os agentes de controle biológico desta praga, tem-se o predador Doru luteipes (Scudder) (Dermaptera: Forficulidae). Porém, a população desse inimigo natural pode ser grandemente prejudicada pelo uso de inseticidas não seletivos. Assim, o uso deste tipo de inseticida é importante para a preservação das espécies benéficas no agroecossistema. A seletividade pode ser classificada em seletividade ecológica e fisiológica (Ripper et al., 1951).

A seletividade fisiológica consiste no uso de inseticidas que sejam mais tóxicos à praga que a seus inimigos na- turais (O’Brien, 1960). Já a seletividade ecológica relaciona-se a formas de utilização dos inseticidas de modo a minimizar a exposição do inimigo natural ao inseticida (Ripper et al., 1951).

Apesar da importância da seletividade na preservação do controle biológico natural de pragas em brássicas, pouco se conhece a esse respeito (Picanço et al., 1997b e 1998). O objetivo deste trabalho foi estudar a seletividade fisiológica dos inseticidas acefato, deltametrina, dimetoato, metamidofós, paratiom metílico e pirimicarbe a quatro estádios de desen- 
Inseticidas seletivos à tesourinha Doru luteipes (Scudder) utilizados no controle do pulgão verde em brássicas.

Tabela 1. Doses (mg de ingrediente ativo/mL) de seis inseticidas para estimativa de curvas de concentração-mortalidade destes para ninfas de último estádio Myzus persicae, adultos e ninfas de primeiro, segundo e terceiro estádio do predador Doru luteipes. Viçosa, UFV, $1996 / 97$.

\begin{tabular}{|c|c|c|c|c|c|c|c|c|c|c|c|c|c|}
\hline \multirow{2}{*}{ Inseticidas } & \multicolumn{13}{|c|}{ Doses usadas (mg de ingrediente ativo/ $\mathrm{mL}$ ) } \\
\hline & \multicolumn{13}{|c|}{ M. persicae } \\
\hline Acefato & 0,005 & & 0,040 & 0,049 & \multicolumn{2}{|c|}{0,060} & 0,100 & \multicolumn{2}{|l|}{0,120} & 0,160 & \multicolumn{2}{|l|}{0,200} & \\
\hline Deltametrina & 0,0006 & & 0,0012 & 0,0018 & \multicolumn{2}{|c|}{0,0023} & 0,0035 & \multicolumn{2}{|c|}{0,0047} & 0,0070 & \multicolumn{2}{|l|}{0,0094} & \\
\hline Dimetoato & 0,024 & & 0,040 & 0,060 & \multicolumn{2}{|c|}{0,100} & 0,120 & \multicolumn{2}{|l|}{0,160} & 0,200 & \multicolumn{2}{|l|}{0,240} & \\
\hline Metamidofós & 0,008 & & 0,017 & 0,025 & \multicolumn{2}{|c|}{0,034} & 0,051 & \multicolumn{2}{|l|}{0,068} & 0,101 & \multicolumn{2}{|l|}{0,135} & \\
\hline Paratiom metílico & 0,0012 & & 0,0030 & 0,0050 & \multicolumn{2}{|c|}{0,0080} & 0,0124 & \multicolumn{2}{|c|}{0,0160} & 0,0200 & \multicolumn{2}{|l|}{0,0220} & 0,0240 \\
\hline Pirimicarbe & 0,0010 & & 0,0019 & 0,0040 & \multicolumn{2}{|c|}{0,0080} & 0,0120 & 0,0160 & & 0,0188 & \multicolumn{2}{|l|}{0,0240} & \\
\hline \multicolumn{14}{|c|}{ Adultos e ninfas de primeiro, segundo e terceiro estádio de $D$. luteipes } \\
\hline Acefato & 0,015 & 0,030 & 0,045 & 0,060 & 0,080 & 0,100 & 0,300 & 0,400 & 0,500 & 0,750 & 1,000 & 1,125 & 1,500 \\
\hline Deltametrina & 0,0028 & 0,0056 & 0,0150 & 0,0263 & 0,0300 & 0,0450 & 0,0600 & 0,0900 & 0,1800 & 0,2438 & & & \\
\hline Dimetoato & 0,015 & 0,020 & 0,030 & 0,050 & 0,060 & 0,080 & 0,100 & 0,525 & 1,000 & 1,125 & 1,200 & 1,500 & 2,000 \\
\hline Metamidofós & 0,010 & 0,013 & 0,015 & 0,020 & 0,040 & 0,050 & 0,080 & 0,090 & 0,100 & 0,200 & 0,400 & 0,500 & 1,000 \\
\hline Paratiom metílico & 0,010 & 0,015 & 0,020 & 0,025 & 0,030 & 0,040 & 0,050 & 0,060 & 0,080 & 0,100 & 1,000 & & \\
\hline Pirimicarbe & 0,1 & 0,5 & 1,0 & 1,6 & 2,0 & 5,0 & 10,0 & 16,0 & 20,0 & 40,0 & 70,0 & & \\
\hline
\end{tabular}

volvimento do predador $D$. luteipes, em relação ao pulgão $M$. persicae.

\section{MATERIAL E MÉTODOS}

O trabalho foi conduzido em laboratório da UFV, em Viçosa (MG), em 1996 e 1997 . Nos bioensaios, foram utilizadas ninfas de último estádio de $M$. persicae e adultos e ninfas de primeiro, segundo e terceiro estádios de $D$. luteipes. Os inseticidas usados foram acefato $750 \mathrm{PM}$, deltametrina $25 \mathrm{CE}$, dimetoato $400 \mathrm{CE}$, metamidofós 600 $\mathrm{CE}$, paratiom metílico $600 \mathrm{CE}$ e pirimicarbe 500 PM.

Para instalação do experimento, folhas de couve do clone portuguesa, completamente desenvolvidas e não infestadas foram imersas em caldas inseticidas por cinco segundos. Em todos os tratamentos (Tabela 1) empregou-se espalhante adesivo N-Dodecil benzeno sulfonato de sódio $320 \mathrm{CE}$ na dose de $0,096 \mathrm{mg}$ de ingrediente ativo/mL de calda (Andrei, 1999). As folhas inteiras foram colocadas para secar por duas horas, e após a secagem, retirou-se da parte central de cada folha um disco foliar de $9 \mathrm{~cm}$ de diâmetro o qual foi acondicionado em placa de Petri de 9 $\mathrm{cm}$ de diâmetro por $2 \mathrm{~cm}$ de altura. Em cada placa, foram liberados 10 insetos provenientes de lavouras de brássicas localizadas no Campus da UFV nas quais não se aplicou inseticida. As placas de Petri foram levadas para incuba- dora a $25 \pm 0,5^{\circ} \mathrm{C}$ e umidade relativa de $75 \pm 5 \%$. Vinte e quatro horas depois foram realizadas contagens do número de insetos mortos por unidade experimental. Os resultados foram corrigidos em relação à mortalidade ocorrida na testemunha, onde somente foi aplicado água e espalhante adesivo, usando-se a fórmula de Abbott (1925). O delineamento experimental foi inteiramente casualizado com quatro repetições. Cada repetição foi constituída por uma placa de Petri contendo 10 insetos.

Determinou-se, por análise de próbite, curvas concentração-mortalidade dos inseticidas para ninfas de último estádio do pulgão, adultos e ninfas de primeiro, segundo e terceiro estádios do predador cuja probabilidade de aceitação do $x^{2}$ fosse maior que 0,05 . Por meio dessas curvas, foram estimadas as concentrações letais para $90 \%$ das populações $\left(\mathrm{CL}_{90}\right)$ (Finney, 1971).

Foram calculados os índice de seletividade diferencial $\left(\mathrm{ISD}_{90}=\mathrm{CL}_{90}\right.$ do inseticida para o predador/ $\mathrm{CL}_{90}$ do inseticida para a praga), de toxicidade relativa $\left(\mathrm{ITR}_{90}=\mathrm{CL}_{90}\right.$ do inseticida com maior valor desta característica para determinado estádio do inseto/ $\mathrm{CL}_{90}$ do inseticida para o inseto) e de tolerância relativa de adultos, ninfas de segundo e terceiro estádios do predador em relação a ninfas de primeiro estádio desse predador $\left(\mathrm{ITRe}_{90}=\mathrm{CL}_{90}\right.$ do inseticida para o de estádio em questão de $D$. luteipes/ $\mathrm{CL}_{90}$ do inseticida para ninfa
I) (Moura et al., 2000).

\section{RESULTADOS E DISCUSSÃO}

A concentração do pirimicarbe que ocasionou $90 \%$ de mortalidade a Myzus persicae $(0,0369 \mathrm{mg}$ de ingrediente ati$\mathrm{vo} / \mathrm{mL}$ ) foi cerca de $3850 ; 349 ; 839$ e 1564 vezes menor que as concentrações que ocasionaram a mesma mortalidade a adultos, ninfas de primeiro, segundo e terceiro estádios do predador $D$. luteipes, respectivamente (Tabela 2). Portanto, o pirimicarbe foi altamente seletivo em favor de todos os estádios de desenvolvimento do predador. Mustafa et al. (1989), observaram boa eficiência do pirimicarbe no controle de Myzus persicae em pimentão e baixo impacto deste produto sobre inimigos naturais Chrysoperla sp. (Neuroptera: Chrysopidae),

Coccinella septempunctata L. (Coleoptera: Coccinellidae), Cylapos sp. (Heteroptera: Miridae) e Aphidius picipes (Nees) (Hymenoptera: Aphidiidae).

A baixa sensibilidade de predadores ao pirimicarbe está associada a alterações na enzima acetilcolinesterase no corpo desses insetos, ou a maior velocidade com que a enzima acetilcolinesterase catalisa a hidrólise do neurotransmissor acetilcolina no predador do que nos pulgões (Silver et al., 1995). A seletividade desse carbamato também pode estar associada à maior 
Tabela 2. Índice de seletividade diferencial $\left(\operatorname{ISD}_{90}{ }^{1}\right)$ e tolerância relativa $\left(\operatorname{ITRe}_{90}{ }^{2}\right)$ de seis inseticidas a adultos e ninfas de primeiro, segundo e terceiro estádios do predador Doru luteipes em relação a ninfas de último estádio de Myzus persicae. Viçosa, UFV, 1996/97.

\begin{tabular}{|c|c|c|c|c|}
\hline \multirow{2}{*}{ Inseticidas } & \multicolumn{4}{|c|}{ ISD $_{90}{ }^{1}$ para os estádios de $D$. luteipes } \\
\hline & Ninfa I & Ninfa II & Ninfa III & Adulto \\
\hline Acefato & $\begin{array}{c}0,56 \\
(0,30-0,96)\end{array}$ & $\begin{array}{c}1,92 \\
(1,02-3,30)\end{array}$ & $\begin{array}{c}2,17 \\
(1,15-3,82)\end{array}$ & $\begin{array}{c}7,33 \\
(3,92-12,84)\end{array}$ \\
\hline Deltametrina & $\begin{array}{c}2,83 \\
(1,73-5,46)\end{array}$ & $\begin{array}{c}2,39 \\
(1,49-4,44)\end{array}$ & $\begin{array}{c}4,26 \\
(2,85-7,19)\end{array}$ & $\begin{array}{c}5,47 \\
(3,30-11,11)\end{array}$ \\
\hline Dimetoato & $\begin{array}{c}0,84 \\
(0,61-1,18)\end{array}$ & $\begin{array}{c}0,67 \\
(0,49-0,96)\end{array}$ & $\begin{array}{c}8,19 \\
(5,08-13,59)\end{array}$ & $\begin{array}{c}13,24 \\
(10,35-17,03)\end{array}$ \\
\hline Metamidofós & $\begin{array}{c}0,64 \\
(0,41-1,12)\end{array}$ & $\begin{array}{c}0,61 \\
(0,41-1,02)\end{array}$ & $\begin{array}{c}1,71 \\
(1,02-3,77)\end{array}$ & $\begin{array}{c}3,24 \\
(2,25-5,10)\end{array}$ \\
\hline Paratiom Metílico & $\begin{array}{c}1,46 \\
(1,02-2,21)\end{array}$ & $\begin{array}{c}3,14 \\
(2,03-5,22)\end{array}$ & $\begin{array}{c}3,25 \\
(2,32-4,56)\end{array}$ & $\begin{array}{c}5,27 \\
(3,11-13,42)\end{array}$ \\
\hline \multirow[t]{3}{*}{ Pirimicarbe } & $\begin{array}{c}349,49 \\
(196,22-600,10) \\
\end{array}$ & $\begin{array}{c}838,76 \\
(404,21-1820,68) \\
\end{array}$ & $\begin{array}{c}1564,48 \\
(823,28-2954,92) \\
\end{array}$ & $\begin{array}{c}3850,38 \\
1973,29-7601,27) \\
\end{array}$ \\
\hline & \multicolumn{4}{|c|}{$\operatorname{ITRe}_{90}{ }^{2}$} \\
\hline & Ninfa II/Ninfa I & Ninfa I & linfa I & Adultos/Ninfa I \\
\hline Acefato & $\begin{array}{c}3,41 \\
(2,07-5,56)\end{array}$ & $\begin{array}{r}3 \\
(2,31\end{array}$ & ,45) & $\begin{array}{c}13,04 \\
(7,92-21,65)\end{array}$ \\
\hline Deltametrina & $\begin{array}{c}0,84 \\
(0,44-1,59)\end{array}$ & $\begin{array}{r}1 \\
(0,84\end{array}$ & $2,58)$ & $\begin{array}{c}1,93 \\
(0,97-3,98)\end{array}$ \\
\hline Dimetoato & $\begin{array}{c}0,80 \\
(0,57-1,16)\end{array}$ & $\begin{array}{r}9 \\
(5,86\end{array}$ & $6,41)$ & $\begin{array}{c}15,76 \\
(11,94-20,55)\end{array}$ \\
\hline Metamidofós & $\begin{array}{c}0,96 \\
(0,59-1,54)\end{array}$ & $\begin{array}{r}2 \\
(1,46\end{array}$ & $5,72)$ & $\begin{array}{c}5,10 \\
(3,24-7,73)\end{array}$ \\
\hline Paratiom Metílico & $\begin{array}{c}2,15 \\
(1,34-3,51)\end{array}$ & $\begin{array}{r}2 \\
(1,53\end{array}$ & ,07) & $\begin{array}{c}3,60 \\
(2,05-9,04)\end{array}$ \\
\hline Pirimicarbe & $\begin{array}{c}2,40 \\
(1,34-4,65)\end{array}$ & $\begin{array}{r}4 \\
(2,74\end{array}$ & ,54) & $\begin{array}{c}11,02 \\
(6,56-19,40)\end{array}$ \\
\hline
\end{tabular}

${ }^{1} \mathrm{ISD}_{90}=\mathrm{CL}_{90}$ do inseticida para o inimigo natural/ $\mathrm{CL}_{90}$ do inseticida para $M$. persicae.

${ }^{2} \mathrm{ITRe}_{90}=\mathrm{CL}_{90}$ do inseticida/ $\mathrm{CL}_{90}$ do inseticida para ninfa I de D. luteipes. Os números entre parêntesis se referem ao intervalo de confiança a $95 \%$ de probabilidade.

taxa de metabolização desse pelo predador do que pela praga por enzimas monooxigenases dependentes de citocromo P450 (Brattsten et al., 1986). Essas enzimas normalmente destoxificam compostos lipofílicos, transformando-os em metabólitos polares, possibilitando sua excreção. Essa hipótese baseia-se na alta lipofilicidade do pirimicarbe $(0,27 \%$ de solubilidade em água) (Farm Chermicals Handbook, 1983), e no fato das monooxigenases dependentes de citocromo P450 serem as principais enzimas envolvidas nos mecanismos metabólicos de redução de toxicidade de carbamatos a insetos (Guedes, 1999).

A concentração da deltametrina que ocasionou $90 \%$ de mortalidade a $M$. persicae $(0,0948 \mathrm{mg}$ de ingrediente ativo/mL) foi cerca de $5 ; 3 ; 2$ e 4 vezes menor que as concentrações que ocasionaram a mesma mortalidade a adultos, ninfas de primeiro, segundo e terceiro estádios do predador, respectivamente (Tabela 2). Assim, esse inseticida pode ser considerado medianamente seletivo em favor de adultos e ninfas de primeiro e terceiro, estádios e pouco seletivo em favor de ninfas de segundo estádio do predador. Faleiro et al. (1995) utilizando as $\mathrm{CL}_{99}$ de deltametrina para Spodoptera frugiperda (Smith) (Lepidoptera: Noctuidae), verificaram que este inseticida também foi seletivo em favor de $D$. luteipes. Resultados semelhantes foram obtidos por Picanço et al. (1996) com os predadores Podisus nigrispinus Bergroth e Supputius cincticeps Stal (Heteroptera: Pentatomidae) em relação a Dione juno juno Cr. (Lepidoptera: Heliconidade).

A concentração do paratiom metílico que ocasionou $90 \%$ de mortalidade a $M$. persicae $(0,0235 \mathrm{mg}$ de ingrediente ati$\mathrm{vo} / \mathrm{mL}$ ) foi cerca de $5 ; 1,5 ; 3$ e 3 vezes menor que as concentrações que ocasionaram a mesma mortalidade a adultos, ninfas de primeiro, segundo e terceiro estádios do predador, respectivamente. Esse inseticida apresentou toxicidade semelhante a $M$. persicae e a ninfas de primeiro estádio do predador (Tabela 2). O paratiom metílico pode ser considerado medianamente seletivo em favor de adultos e ninfas de segundo e terceiro, estádios e pouco seletivo em favor de 
Tabela 3. Índices de toxicidade relativa (ITR) de seis inseticidas para ninfas de último estádio Myzus persicae e adultos e ninfas de primeiro, segundo e terceiro estádios do predador Doru luteipes. Viçosa, UFV, 1996/97.

\begin{tabular}{|c|c|c|c|c|c|}
\hline \multirow[b]{2}{*}{ Inseticida } & \multicolumn{5}{|c|}{ ITR $_{90}{ }^{1}$} \\
\hline & M. persicae & $\begin{array}{l}\text { Ninfa I de } \\
\text { D. Iuteipes }\end{array}$ & $\begin{array}{l}\text { Ninfa II de } \\
\text { D. luteipes }\end{array}$ & $\begin{array}{l}\text { Ninfa III de } \\
\text { D. luteipes }\end{array}$ & $\begin{array}{l}\text { Adulto de } \\
\text { D. luteipes }\end{array}$ \\
\hline Acefato & $\begin{array}{c}1,00 \\
(0,51-1,95)\end{array}$ & $\begin{array}{c}82,35 \\
(51,89-129,30)\end{array}$ & $\begin{array}{c}57,89 \\
(31,29-116,60)\end{array}$ & $\begin{array}{c}95,67 \\
(54,92-169,19)\end{array}$ & $\begin{array}{c}69,55 \\
(39,20-127,14)\end{array}$ \\
\hline Deltametrina & $\begin{array}{c}2,94 \\
(1,83-5,73)\end{array}$ & $\begin{array}{c}48,01 \\
(26,98-80,94)\end{array}$ & $\begin{array}{c}136,47 \\
(68,37-284,35)\end{array}$ & $\begin{array}{c}143,11 \\
(85,95-242,18)\end{array}$ & $\begin{array}{c}274,23 \\
(133,36-537,60)\end{array}$ \\
\hline Dimetoato & $\begin{array}{c}2,08 \\
(1,35-3,57)\end{array}$ & $\begin{array}{c}114,73 \\
(77,89-169,59)\end{array}$ & $\begin{array}{c}343,13 \\
(197,22-635,61)\end{array}$ & $\begin{array}{c}52,68 \\
(28,31-100,19)\end{array}$ & $\begin{array}{c}80,19 \\
(54,16-126,55)\end{array}$ \\
\hline Metamidofós & $\begin{array}{c}1,78 \\
(1,11-3,47)\end{array}$ & $\begin{array}{c}129,61 \\
(79,57-207,11)\end{array}$ & $\begin{array}{c}323,41 \\
(180,57-627,58)\end{array}$ & $\begin{array}{c}215,49 \\
(99,18-410,11)\end{array}$ & $\begin{array}{c}280,23 \\
(175,81-476,83)\end{array}$ \\
\hline m metílico & $\begin{array}{c}11,86 \\
(7,42-21,02)\end{array}$ & $\begin{array}{c}374,89 \\
(244,72-557,23)\end{array}$ & $\begin{array}{c}419,38 \\
(213,26-849,65)\end{array}$ & $\begin{array}{c}756,61 \\
(496,88-1207,62)\end{array}$ & $\begin{array}{c}1147,65 \\
(404,76-2313,43)\end{array}$ \\
\hline Pirimic & $\begin{array}{c}7,55 \\
(3,92-15,24)\end{array}$ & $\begin{array}{c}1,00 \\
(0,65-1,53)\end{array}$ & $\begin{array}{c}1,00 \\
(0,44-2,26)\end{array}$ & $\begin{array}{c}1,00 \\
(0,56-1,80)\end{array}$ & $\begin{array}{c}1,00 \\
(0,52-1,93)\end{array}$ \\
\hline
\end{tabular}

${ }^{1} \mathrm{ITR}_{90}=$ Razão da $\mathrm{CL}_{90}$ menos tóxica/ $\mathrm{CL}_{90}$ do inseticida para o estádio e espécie em questão. Os números entre parêntesis se referem ao intervalo de confiança dos $\operatorname{ITR}_{90}$ a $95 \%$ de probabilidade.

ninfas de primeiro estádio do predador. Heinrichs et al. (1979) não constataram efeitos adversos do paratiom metílico sobre larvas e adultos do predador Calosoma granulatum Perty (Coleoptera: Carabidae). Já Picanço et al. (1997a), utilizando dose recomendada de paratiom metílico para $S$. frugiperda $(0,72 \mathrm{mg}$ de ingrediente ativo/mL), verificaram que este inseticida foi altamente tóxico a $D$. luteipes.

A concentração do dimetoato que ocasionou $90 \%$ de mortalidade a $M$. persicae $(0,1338 \mathrm{mg}$ de ingrediente ati$\mathrm{vo} / \mathrm{mL}$ ) foi cerca de 13 e 8 vezes menor que as concentrações que ocasionaram a mesma mortalidade a adultos e ninfas de terceiro estádio de $D$. luteipes, respectivamente. $\mathrm{O}$ dimetoato apresentou toxicidade semelhante a $M$. persicae e a ninfas de primeiro e segundo estádios do predador (Tabela 2). O dimetoato foi medianamente seletivo em favor de adultos e ninfas de terceiro estádio e prejudicial a ninfas primeiro e segundo estádios desse predador. Powell \& Scott (1991) estudando seletividade de inseticidas a Microplitis croceipes (Cresson) (Hymenoptera: Braconidae), verificaram que o dimetoato apresentou seletividade em favor deste parasitóide.

A concentração do acefato que ocasionou $90 \%$ de mortalidade a $M$. persicae $(0,2787 \mathrm{mg}$ de ingrediente ati-
vo/mL) foi cerca de 7; 2 e 2 vezes menor que as concentrações que ocasionaram a mesma mortalidade a adultos, ninfas de segundo e terceiro estádios de D. luteipes, respectivamente. A concentração desse inseticida foi cerca de duas vezes maior para ninfas de primeiro estádio do predador do que para $M$. persicae (Tabela 2). $\mathrm{O}$ acefato pode ser considerado medianamente seletivo em favor de adultos, pouco seletivo em favor de ninfas de segundo e terceiro estádios e prejudicial a ninfas de primeiro estádio do predador. Bayoun et al. (1995) estudando a seletividade de inseticidas em favor de inimigos naturais de Diuraphis noxia Kurdyumov (Homoptera: Aphididae), observaram que o acefato foi o inseticida menos tóxico aos predadores Hippodamia convergens (Guérin-Méneville), Hippodamia variegata (Goeze), Hippodamia sinuata (Mulsant) e $C$. septempunctata (Coleoptera: Coccinellidae) e aos Hymenoptera parasitóides Diaeretiella rapae (M'Intosh) (Braconidae), Aphelinus varipes (Foerster) (Aphelinidae) e Lysiphlebus testaceipes (Cresson) (Aphidiidae) deste pulgão.

A concentração do metamidofós que ocasionou $90 \%$ de mortalidade a $M$. persicae $(0,1565 \mathrm{mg}$ de ingrediente ati$\mathrm{vo} / \mathrm{mL}$ ) foi cerca de 3 e 2 vezes menor que as concentrações que ocasionaram a mesma mortalidade a adultos e ninfas de terceiro estádio de $D$. luteipes. A concentração desse inseticida foi duas vezes maior para ninfas de primeiro e segundo estádios do predador do que para M. persicae (Tabela 2). Baseado nesses resultados conclui-se que o metamidofós é medianamente seletivo em favor de adultos e pouco seletivo em favor de ninfas de terceiro estádio do predador e prejudicial a ninfas de primeiro e segundo estádios do predador.

Segundo Stock \& Holloway (1993) substâncias com pesos moleculares maiores possuem menor capacidade de penetração na cutícula do inseto. As toxicidades do dimetoato e metamidofós a ninfas de primeiro e segundo estádios do predador e a do acefato para ninfas de primeiro estádio do predador, possivelmente, estejam relacionadas com o baixo peso molecular destes compostos $(229,28 ; 141,12$ e 183,16 , respectivamente), uma vez que estes inseticidas apresentam os menores pesos moleculares entre os produtos testados (Farm Chermicals Handbook, 1983).

De modo geral os inseticidas apresentaram certa seletividade em favor de adultos de D. luteipes. Este fato, possivelmente, se deva ao maior volume corporal do predador em relação a sua presa. Esta hipótese é fundamentada em 
Tabela 4. Equações, concentrações letais $\left(\mathrm{CL}_{90}\right)$, qui-quadrado $\left(\mathrm{x}^{2}\right)$ e probabilidade das curvas de concentração-mortalidade de seis inseticidas à ninfas de último estádio Myzus persicae, adultos e ninfas de primeiro, segundo e terceiro estádio do predador Doru luteipes. Viçosa, UFV, 1996/97.

\begin{tabular}{|c|c|c|c|c|c|}
\hline Inseticidas & Equação $^{1}$ & $\mathbf{R}^{2}$ & $\begin{array}{c}\mathrm{CL}_{90}{ }^{2} \\
\text { (mg de i.a./ } \mathrm{mL} \text { ) }\end{array}$ & $\chi^{2}$ & Probabilidade \\
\hline \multicolumn{6}{|c|}{ M. persicae } \\
\hline Acefato & $Y^{\prime}=7,53+2,26 X$ & 0,9721 & $0,2787(0,2136-0,4161)$ & 2,563 & 0,2770 \\
\hline Deltametrina & $Y^{\prime}=7,74+1,43 X$ & 0,9803 & $0,0948(0,0726-0,1170)$ & 3,012 & 0,3908 \\
\hline Dimetoato & $Y^{\prime}=8,44+2,47 X$ & 0,9662 & $0,1338(0,1166-0,1584)$ & 5,919 & 0,3138 \\
\hline Metamidofós & $Y^{\prime}=7,54+1,56 X$ & 0,9715 & $0,1565(0,1199-0,1931)$ & 0,624 & 0,7365 \\
\hline Paratiom metílico & $Y^{\prime}=9,48+1,97 X$ & 0,9920 & $0,0235(0,0198-0,0288)$ & 1,589 & 0,8128 \\
\hline Pirimicarbe & $Y^{\prime}=8,68+1,68 X$ & 0,9712 & $0,0369(0,0273-0,0545)$ & 5,604 & 0,1307 \\
\hline \multicolumn{6}{|c|}{ Ninfa I de $D$. Iuteipes } \\
\hline Acefato & $Y^{\prime}=7,88+1,98 X$ & 0,9692 & $0,1566(0,1267-0,2061)$ & 7,583 & 0,1068 \\
\hline Deltametrina & $Y^{\prime}=7,38+1,93 X$ & 0,9733 & $0,2686(0,2024-0,3964)$ & 3,893 & 0,2724 \\
\hline Dimetoato & $Y^{\prime}=9,20+3,07 X$ & 0,9877 & $0,1124(0,0966-0,1373)$ & 1,866 & 0,6047 \\
\hline Metamidofós & $Y^{\prime}=8,34+2,06 X$ & 0,9863 & $0,0995(0,0791-0,1344)$ & 2,739 & 0,5644 \\
\hline Paratiom metílico & $Y^{\prime}=10,39+2,81 X$ & 0,9188 & $0,0344(0,0294-0,0437)$ & 5,788 & 0,0539 \\
\hline Pirimicarbe & $Y^{\prime}=3,61+2,41 X$ & 0,9803 & $12,8962(10,6942-16,3826)$ & 4,191 & 0,2403 \\
\hline \multicolumn{6}{|c|}{ Ninfa II de D. luteipes } \\
\hline Acefato & $Y^{\prime}=6,80+1,90 X$ & 0,9908 & $0,5346(0,4263-0,7041)$ & 3,049 & 0,3851 \\
\hline Deltametrina & $Y^{\prime}=7,84+2,43 X$ & 0,9605 & $0,2268(0,1748-0,3222)$ & 5,898 & 0,0510 \\
\hline Dimetoato & $Y^{\prime}=9,80+3,37 X$ & 0,9779 & $0,0902(0,0782-0,1117)$ & 1,965 & 0,6239 \\
\hline Metamidofós & $Y^{\prime}=9,27+2,93 X$ & 0,9966 & $0,0957(0,0792-0,1220)$ & 0,863 & 0,6554 \\
\hline Paratiom metílico & $Y^{\prime}=8,26+1,74 X$ & 0,8968 & $0,0738(0,0585-0,1033)$ & 5,776 & 0,0542 \\
\hline Pirimicarbe & $Y^{\prime}=3,50+1,86 X$ & 0,9672 & $30,9503(22,0293-49,7047)$ & 3,735 & 0,1520 \\
\hline \multicolumn{6}{|c|}{ Ninfa III de $D$. luteipes } \\
\hline Acefato & $Y^{\prime}=6,75+2,12 X$ & 0,9937 & $0,6034(0,4768-0,8170)$ & 1,288 & 0,5304 \\
\hline Deltametrina & $Y^{\prime}=7,48+3,06 X$ & 0,9669 & $0,4034(0,3331-0,5220)$ & 4,282 & 0,1151 \\
\hline Dimetoato & $Y^{\prime}=6,22+1,63 X$ & 0,9810 & $1,0959(0,8052-1,5849)$ & 4,592 & 0,0983 \\
\hline Metamidofós & $Y^{\prime}=8,07+3,12 X$ & 0,9175 & $0,2679(0,1967-0,4524)$ & 4,742 & 0,0911 \\
\hline Paratiom metílico & $Y^{\prime}=9,55+2,93 X$ & 0,9876 & $0,0763(0,0668-0,0903)$ & 2,417 & 0,5067 \\
\hline Pirimicarbe & $Y^{\prime}=2,56+2,12 X$ & 0,9708 & $57,7292(44,8685-80,6693)$ & 4,608 & 0,2012 \\
\hline \multicolumn{6}{|c|}{ Adultos de $D$. Iuteipes } \\
\hline Acefato & $Y^{\prime}=5,57+2,29 X$ & 0,9972 & $2,0428(1,6322-2,7434)$ & 0,704 & 0,7086 \\
\hline Deltametrina & $Y^{\prime}=7,03+2,63 X$ & 0,9789 & $0,5181(0,3860-0,8064)$ & 2,254 & 0,3245 \\
\hline Dimetoato & $Y^{\prime}=4,73+6,25 X$ & 0,9525 & $1,7718(1,6398-1,9856)$ & 4,148 & 0,1232 \\
\hline Metamidofós & $Y^{\prime}=7,13+2,89 X$ & 0,9900 & $0,5070(0,4352-0,6117)$ & 1,203 & 0,5533 \\
\hline Paratiom metílico & $Y^{\prime}=8,00+1,89 X$ & 0,9952 & $0,1238(0,0897-0,2657)$ & 0,097 & 0,9523 \\
\hline Pirimicarbe & $Y^{\prime}=1,63+2,16 X$ & 0,9746 & $142,0791(107,5445-207,5147)$ & 3,270 & 0,1928 \\
\hline
\end{tabular}

${ }^{1} \mathrm{Y}^{\prime}=$ Mortalidade em próbite e; $\mathrm{X}=$ logaritmo da concentração (mg de ingrediente ativo $/ \mathrm{mL}$ ).

${ }^{2}$ Os números entre parêntesis se referem ao intervalo de confiança das $\mathrm{CL}_{90}$ a $95 \%$ de probabilidade.

observações feitas por Rathman et al. (1992) com o parasitóide de pulgões Diglyphus begini (Ashmead) (Hymenoptera: Eulophidae) e por Picanço et al. (1997b) com o percevejo predador $P$. nigrispinus, que verificaram que as maiores tolerâncias de insetos a inseticidas estavam relacionadas ao seu maior volume corporal, e conseqüente menor área específica, o que confere menor exposição aos inseticidas.
Adultos, ninfas de segundo e terceiro estádios de $D$. luteipes foram cerca de $13 ; 3$ e 4 vezes mais tolerantes ao acefato; $4 ; 2$ e 2 vezes mais tolerantes ao paratiom metílico e 11; 2 e 4 vezes mais tolerantes ao pirimicarbe do que 
ninfas de primeiro estádio, respectivamente. Adultos e ninfas de terceiro estádio de $D$. luteipes foram cerca de 2 vezes mais tolerantes a deltametrina; 16 e 10 vezes mais tolerantes ao dimetoato e 5 e 3 vezes mais tolerantes ao metamidofós do que ninfas de primeiro estádio desse predador, respectivamente. Ninfas de primeiro e segundo estádios apresentaram tolerância semelhante aos inseticidas deltametrina, dimetoato e metamidofós (Tabela 2).

$\mathrm{O}$ acefato apresentou a menor potência à $M$. persicae possuindo a maior $\mathrm{CL}_{90}$ entre os inseticidas estudados. Seus valores de índice de toxidade relativa foram tomados como iguais a um, e utilizados como referencial nas comparações, indicando quantas vezes um inseticida é mais potente que outro. Paratiom metílico e pirimicarbe foram os inseticidas mais potentes ao pulgão, seguidos pela deltametrina, dimetoato e metamidofós (Tabelas 3 e 4).

$\mathrm{O}$ pirimicarbe foi o inseticida menos potente a todos os estádios de desenvolvimento do predador. Já paratiom metílico foi o inseticida mais potente a D. luteipes sendo cerca de $1148 ; 375$, 419 e 757 vezes mais potente que o pirimicarbe a adultos, ninfas de primeiro, segundo e terceiro estádios do predador, respectivamente (Tabelas 3 e 4).

As curvas de concentração-mortalidade de deltametrina, metamidofós e pirimicarbe (para todos os estádios de desenvolvimento de D. luteipes), dimetoato (para adultos e ninfas de primeiro e segundo estádios), paratiom metílico (para ninfas de primeiro e terceiro estádios) e acefato (para adultos), apresentaram maiores inclinações do que as curvas destes inseticidas para $M$. persicae (Tabela 4). As maiores inclinações apresentadas pelas curvas concentração-mortalidade dos inseticidas para o predador do que para M. persicae, indicam que pequenas variações nas doses desses inseticidas ocasionaram maiores variações nas mortalidades do predador do que para a praga. Assim, é de extrema importância a calibração correta das doses desses inseticidas para se evitar efeitos nocivos desses inseticidas sobre esse predador.

\section{LITERATURA CITADA}

ABBOTT, W.S. A method of computing the effectiveness of an insecticide. Journal of Economic Entomology, v. 18, n. 4, p. 265-267, 1925.

ANDREI, E. Compêndio de defensivos agrícolas. 6 ed. São Paulo: Andrei, 1999. 676 p.

BAYOUN, I.M.; PLAPP Jr., F.W.; GILSTRAP, F.E.; MICHELS Jr., G.J. Toxicity of selected insecticides to Diuraphis noxia (Homoptera: Aphididae) and its natural enemies. Journal of Economic Entomology, v. 88, n. 5, p. 1177-1185, 1995.

BRATTSTEN, L.B.; HOLYOKE, J.R.; LEEPER, J.R.; RAFFA, K.F. Insecticide resistance: Challenge to pest management and basic research. Science, v. 231, p. 1255-1260, 1986.

CATIE. Guía para el manejo integrado de plagas del cultivo de repollo. Turrialba: CATIE, 1990.81 p. FALEIRO, F.G.; PICANÇO, M.C.; PAULA, S.V.; BATALHA, V.C. Seletividade de inseticidas a Spodoptera frugiperda (J.E. Smith) (Lepidoptera: Noctuidae) e ao predador Doru luteipes (Scudder) (Dermaptera: Forficulidae). Anais da Sociedade Entomológica do Brasil, Londrina, v. 24, n. 2, p. 247-252, 1995.

FARM CHEMICALS HANDBOOK. Pesticide dictionary. Willoughby: Meister, 1983. 264 p.

FINNEY, D.J. Probit analysis. London: Cambridge University, 1971. 333 p.

GUEDES, R.N.C. Resistência de insetos a inseticidas. In: ZAMBOLIN, L. ed. Manejo integrado de doenças e pragas. Viçosa: UFV, 1999. p. 101-107. HEINRICHS, E.A.; GASTAL, H.O.; GALILEO, M.H.M. Incidence of natural agents of the velvet bean caterpillar and response of its predators to insecticide treatments in Brazilian soybean fields. Pesquisa Agropecuária Brasileira, Brasília, v. 14, n. 1, p. $79-87,1979$

MOURA, M.F.; PICANÇO, M.; GONRING, A.H.R.; BRUCKNER, C.H. Seletividade de inseticidas a três Vespidae predadores de Dione juno juno (Lepidoptera: Heliconidae). Pesquisa Agropecuária Brasileira, Brasília, v. 35, n. 2, p. 251-257, 2000.
MUSTAFA, M.T.; HAMDAN, A.S.; SHURAIQI, Y. Toxicity of certain insecticides to the green peach aphid. Tropical Pest Management, v. 35, n. 4, p. 359-361, 1989.

O'BRIEN, R.D. Toxic phosphorus esters. New York: Academic, 1960. 434 p.

PICANÇO, M.C.; GUEDES, R.N.C.; BATALHA, V.C.; CAMPOS, R.P. Toxicity of insecticides to Dione juno juno (Lepidoptera: Heliconidae) and selectivity to two of its predaceous bugs. Tropical Science, v. 36, n. 1, p. 51-53, 1996.

PICANÇO, M.; LÔBO, A.P.; SILVA, E.A.; LEITE, G.L.D. Seletividade a Doru luteipes de inseticidas utilizados no controle de Spodoptera frugiperda. Científica, São Paulo, v. 25, n. 1, p. 187-194, 1997a.

PICANÇO, M.; RIBEIRO, L.J.; LEITE, G.L.D.; ZANUNCIO, J.C. Seletividade de inseticidas a Podisus nigrispinus predador de Ascia monuste orseis. Pesquisa Agropecuária Brasileira, Brasília, v. 32, n. 4, p. 369-372, 1997 b.

PICANÇO, M.; RIBEIRO, L.J.; LEITE, G.L.D.; GUSMÃO, M.R. Seletividade de inseticidas a Polybia ignobilis (Haliday) (Hymenoptera: Vespidae) predador de Ascia monuste orseis (Godart) (Lepidoptera: Pieridae). Anais da Sociedade Entomológica do Brasil, Londrina, v. 27, n. 1, p. 85-90, 1998.

POWELL, J.E.; SCOTT, W.P. Survival of Microplitis croceipes (Hymenoptera: Braconidae) in contact with residues of insecticides on cotton. Journal of Economic Entomology, v. 20, n. 1, p. 346- 348, 1991.

RATHMAN, R.J.; JOHNSON, M.W.; ROSENHEIM, J.A.; TABASHNIK, B.E.; PURCELL, M. Sexual differences in insecticide susceptibility and synergism with piperonyl butoxide in the leafminer parasitoid Diglyphus begini (Hymenoptera: Eulophidae). Journal of Economic Entomology, v. 85, n. 1, p. 15-20, 1992. RIPPER, W.E.; GREENSLADE, R.M.; HARTLEY, G.S. Selective insecticides and biological control. Journal of Economic Entomology, v. 44, n. 4, p. 448-459, 1951.

SILVER, A.R.J.; VAN EMDEN, H.F.; BATTERSBY, M. A biochemical mechanism of resistance to pirimicarb in two glasshouse clones of Aphis gossypii. Pesticide Science, v. 43, n. 1, p. 21-29, 1995.

STOCK, D.; HOLlOWAY, P.J. Possible mechanisms for surfactant-induced foliar uptake of agrochemicals. Pesticide Science, v. 38, n. 2-3, p. $165-177,1993$. 